\title{
G. Crespí de Valldaura y Bosch Labrús (ed.), Diario del Señor D. Cristóval Crespi desde el día en que fue nombrado presidente del Consejo de Aragón, 9 de junio 1652, Madrid, Boletín Oficial del Estado / Generalitat de Catalunya, 2014, XXXIII, 4I3 pp. ISBN 978-84-393-9142-5
}

Don Cristoval Crespí de Valdaura, natural de San Mateo, fue hijo natural de don Francisco y doña Juana Brizuela, y hermano del reverendo y excelentísimo señor don Luís Crespí de Borja. Estudió gramática y filosofía en esta universidad y leyes en Salamanca. Después, restituyéndose a Valencia, obtuvo cátedra de jurisprudencia en esta universidad. Fue oidor criminal y civil de nuestra audiencia, gran cruz y clavero en la religión de Montesa, regente y vicecanciller del sacro Supremo Consejo de Aragón y otro de los governadores de la monarquía española a la menor edad del seńor rey don Carlos II. Murió en la corte a 22 de febrero de I67I, a los 72 de su edad. Enriqueció el orbe literario con sus preciosas observaciones.

(J. Orient, I665)

Aquest fragment, que descriu alguns fets de la vida de Cristòfor Crespí de Valldaura i Brizuela (I599-I67I), pot llegir-se als peus d'un retrat seu, atribuït al pintor José Orient. El quadre, que data de l'any I665, forma part de la col.lecció de l'àrea de conservació del patrimoni cultural de la Universitat de València i es troba exposat en l'edifici d'estudis generals del paranimf de dita universitat.

La pintura enalteix la figura de Cristòfor Crespí, un jurista i escriptor valencià que, al llarg de la seua vida, va ocupar diversos càrrecs polítics i institucionals de responsabilitat. Així, va ser assessor del governador de València per a causes civils (I627), advocat de les sales criminals i civils (I635), regent del Consell Superior d'Aragó (I642), vicecanceller d'aquest Consell (I652) o clavari major i assessor major de l'orde de Montesa (I644). El pinacle de la seua carrera va arribar quan el van nomenar membre de la Junta de Regència per a la minoria d'edat del rei Felip IV (I665). Com a autor, va escriure les Observationes illustratae decisionibus Sacri Regii Aragonum Consilii, un tractat de justícia en què exposa algunes consideracions del seu pas pel Consell del Tribunal Suprem d'Apel-lació de la Corona d'Aragó, a més d'un dietari que va escriure entre els anys I652 i I67I. Aquest dietari, que Crespí va iniciar el diumenge 9 de juny de I652, 
el mateix dia en què va ser nomenat vicecanceller del Consell Superior d'Aragó, i va continuar fins la seua mort, és l'obra que ara ens ocupa. L'edició, a més del mateix text inclou una presentació del diari a càrrec del jurista i historiador Feliciano Barrios i una introducció de Gonzalo Crespí, en què es resumeixen les dades bàsiques de l'autor.

El dietari original, que es troba en la Biblioteca Nacional d'Espanya, es conserva en molt bon estat. Segons l'editor (p. XXIII) sembla que no va ser escrit per Cristòfor mateix, sinó per dues mans diferents. D'aquesta manera, a partir del foli 74 (corresponent al dissabte 2 I de febrer de I654), s'observen canvis notables en la lletra, que es torna més rodona i espaiada, i el nombre de línies per pàgina es redueix. També pareix que el dietari va ser escrit per algú proper — possiblement un secretari- tot d'una tirada després de la mort de Crespí. I és que no s’hi percep cap canvi en el tipus de tinta emprada, ni tan sols en el fragment en què es narra la mort de l'autor, un passatge que, evidentment, no va escriure ell. L'editor argumenta que la hipòtesi més probable és que el manuscrit fóra una recopilació de notes, tal vegada dictades, que algun successor en el càrrec va ordenar transcriure.

Més de tres segles després de la redacció del text, un dels descendents de l'autor ha editat l'obra de l'avantpassat. Així, el matrimoni de Cristòfor Crespí amb Vicenta Calatayud va tenir tres fills: Joana, Francesc i Aldonça. Tanmateix, solament la primera va sobreviure a la infantesa. Al seu torn, Joana es va casar amb Feliu Brondo, marqués de Villasidro i baró de la Joiosa Guarda, i va tenir dos fills, Maria Lluïsa i Cristòfor. És a través de la descendència de Maria Lluïsa que connectem amb l'editor del dietari, Gonzalo Crespí.

Tal com indica Barrios en la presentació del volum, hem de ser conscients que estem davant del dietari d'un dels més alts dignataris del seu temps; de tal manera, com a vicecanceller d'Aragó, "protocol-làriament només era precedit pels membres de la família reial i el president del Consell de Castella» (p. Ix). Consegüentment, el text està farcit de dades que ens informen sobre el funcionament de les més elevades institucions de l'Estat i els successos polítics del seu temps. En la seua presentació, Barrios fa un resum de les dades donades per Cristòfor Crespí i il-lustra els consells existents durant els regnats de Felip IV i Carles II d'Espanya, quines eren les seues tasques, com es classificaven i qui els componia.

No obstant això, també és important assenyalar que el dietari dóna molt poca informació sobre la vida privada de l'autor. És freqüent trobar entrades en blanc, de dies en què probablement no va ocòrrer res que Crespí considerara notori d'anotar, per tal com el seu dia a dia no era per a ell matèria digna de memòria. Tant és així que, de vegades, deixa entreveure que només s'ocupa en transcriure aquells esdeveniments que considera rellevants, com quan afirma que «las demás cosas particulares que pasaron no refiero porque su memoria no es de importancia para otras ocasiones» (p. 4I). Junt 
amb aquestes entrades, conviuen altres fragments de temàtica privada que, per la seua rellevància, Cristòfor sí que descriu, però sempre d'una manera asèptica i despullada de qualsevol emoció. El del casament de la seua filla Joana n'és un exemple significatiu, on, abans de repassar una escassa llista de convidats, es narra (p. I3):

Domingo a 8. Se capituló y desposó Juana, mi hija. Reçeiveron las capitulaziones Baltasar Cerdán, secretario de S. M., y Pedro Navarro de Aguirri, notario de Valençia. Desposoles don Joseph de Castelví, canónigo de la santa iglesia de Caller, hermano del seńor don Jorge de Castelví, que fue el que se desposó en nombre de su sobrino el marqués de Villaçidro. No quise que concurriese nadie, sino mui en secreto.

A causa d'aquesta absència d'intimisme, resulta complex extraure conclusions sobre la personalitat de Cristòfor Crespí i solament en podem inferir-ne algunes poques característiques a partir de l'escrit. Sabem, per exemple, que avorreix l'excessiu protocol de les institucions i que, tot i que assisteix algunes vegades als bous, en realitat no l'entusiasmen i solament acudeix perquè li semblen «obligaçión del ofiçio» (p. 7). En aquest sentit, és d'agrair la introducció del Gonzalo Crespí, que sintetitza les dades més rellevants del seu avantpassat i el seu dietari. En la mateixa línia, és també molt significatiu l'índex temàtic final, que permet localitzar de manera ràpida un grapat d'esdeveniments històrics, successos personals i altres notícies diverses no relacionades amb el món de la política.

Pel que fa als criteris d'edició, cal dir que l'editor s'ha limitat a regularitzar tan sols l'accentuació, els signes de puntuació, l'ús de majúscules i minúscules, la desfeta de les abreviatures i la desunió de les paraules que apareixien unides en l'original. $\mathrm{Al}$ nostre parer, aquests criteris són excessivament parcs i hauria calgut potser aplicar criteris diplomaticointerpretatius o de regularització de les grafies, que haurien ajudat a ampliar el nombre de lectors d'aquestes interessants memòries de l'edat moderna. De la mateixa manera, s'hi troba a faltar una puntuació més precisa que facilite la lectura, així com notes a peu de pàgina que aclarisquen els llocs, moments i persones que se citen.

En definitiva, podem dir que estem davant de l'edició d'un dietari que, tot i que no aprofundeix de manera significativa en la personalitat i vida d'aquest jurista, sí que dóna un bon munt d'informació històrica i política sobre el funcionament de les altes institucions del Govern espanyol a mitjan segle xvir. Seran els lectors a la recerca d'aquest tipus d'informació els que més interessants trobaran les cavil.lacions de Cristòfor Crespí de Valldaura.

\author{
Carlos Martínez MaYor \\ Universitat de València \\ marmaca4@alumni.uv.es
}




\section{REFERÈNCIES BIBLIOGRÀFIQUES}

Crespí de Valldaura i Bosch Labrús, G,. ed. (20I4), Diario del señor don Cristóval Crespi desde el día en que fue nombrado presidente del consejo de Aragon (o de junio de I652), Madrid, Generalitat de Catalunya i Agencia Estatal del Boletín Oficial del Estado.

Escartí, V. (20I6), "Les memòries de Cristòfor Crespí», en Levante-El Mercantil Valenciano, 7 de desembre, p. 54.

Orient, J. (I665), Cristóbal Crespi de Valldaura, recuperat de <https://goo.gl/IV3fjt $>$ [consultat el 27 de desembre de 20i6]. 